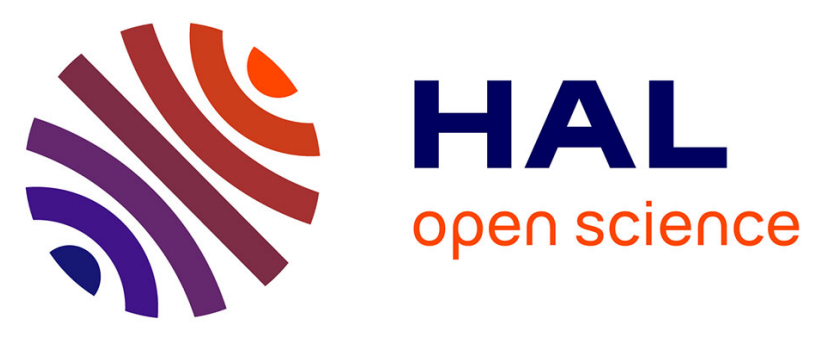

\title{
Influence of tetrabutylammonium chloride on the electrodeposition of indium from chloride solution on a glassy carbon electrode
}

Khaisa Avchukir, Bibissara Dzhalmukhamedovna Burkitbayeva, Florence

Vacandio, Akmaral Mukhambetovna Argimbayeva, Gulmira Rakhymbay

\section{To cite this version:}

Khaisa Avchukir, Bibissara Dzhalmukhamedovna Burkitbayeva, Florence Vacandio, Akmaral Mukhambetovna Argimbayeva, Gulmira Rakhymbay. Influence of tetrabutylammonium chloride on the electrodeposition of indium from chloride solution on a glassy carbon electrode. Journal of Electroanalytical Chemistry, 2019, 842, pp.176-183. 10.1016/j.jelechem.2019.04.078 . hal-02649527

\section{HAL Id: hal-02649527 \\ https://hal-amu.archives-ouvertes.fr/hal-02649527}

Submitted on 29 May 2020

HAL is a multi-disciplinary open access archive for the deposit and dissemination of scientific research documents, whether they are published or not. The documents may come from teaching and research institutions in France or abroad, or from public or private research centers.
L'archive ouverte pluridisciplinaire HAL, est destinée au dépôt et à la diffusion de documents scientifiques de niveau recherche, publiés ou non, émanant des établissements d'enseignement et de recherche français ou étrangers, des laboratoires publics ou privés. 
Influence of tetrabutylammonium chloride on the electrodeposition of indium from chloride solution on a glassy carbon electrode

Khaisa Avchukir ${ }^{1,2, *}$, Bibissara Dzhalmukhamedovna Burkitbayeva ${ }^{1}$, Florence Vacandio ${ }^{2}$, Akmaral Mukhambetovna Argimbayeva ${ }^{1}$, Gulmira Rakhymbay ${ }^{1}$

${ }^{1}$ Center of Physical Chemical Methods of Research and Analysis, Faculty of Chemistry and Chemical Technology, Al-Farabi Kazakh National University, 050012 Almaty, 96a Tole bi Str., Kazakhstan ${ }^{2}$ Aix-Marseille University, CNRS, MADIREL UMR 7246, 13397 Marseille cedex 20, France

${ }^{*}$ Corresponding author: 050012 Almaty, 96a Tole bi Str., Kazakhstan.

Tel: +7 7272923731 , Fax: +7 7272923731

E-mail address: khaisa.avchukir@cfhma.kz

\begin{abstract}
In this paper, the electrochemical reduction of indium on a glassy carbon electrode (GCE) in a chloride electrolyte in the presence of tetrabutylammonium chloride (TBACh) was studied using the rotating disk electrode method, chronoamperometry and scanning electron microscopy. It was found that the addition of TBACh inhibits the electroreduction of indium by increasing the activation energy of the process by $17 \mathrm{~kJ} \mathrm{~mol}^{-1}$, and also shows leveling action at its low concentrations. The diffusion coefficient of indium (III) ions found from Levich equation at $25^{\circ} \mathrm{C}$, was $4.93 \times 10^{-6} \mathrm{~cm}^{2} \mathrm{~s}^{-1}$. The $\mathrm{In}^{3+}$ diffusion coefficient determined using the Levich equation are consistent with the values determined by the Cottrell law and universal Stokes-Einstein equation. The addition of $10^{-4} \mathrm{M}$ TBACh to the electrolyte reduces the diffusion coefficient to $2.13 \times 10^{-6} \mathrm{~cm}^{2} \mathrm{~s}^{-1}$.
\end{abstract}


The type of crystallization corresponding to the progressive 3D nucleation with diffusion control has been established. Using the Scharifker-Hills, Scharifker-Mostany and Mirkin-Nilov-Heerman-Tarallo models nucleation parameters were calculated, which correlate well with the results of scanning electron microscopy. Addition of TBACh increases the nucleation rate at $-0.90 \mathrm{~V}$ from $9.19 \times 10^{6} \mathrm{~cm}^{-}$ ${ }^{2} \mathrm{~s}^{-1}$ to $48.09 \times 10^{6} \mathrm{~cm}^{-2} \mathrm{~s}^{-1}$ and reduces the average radius of grains of indium coatings from $18.0 \mu \mathrm{m}$ to $6.8 \mu \mathrm{m}$.

\section{Keywords}

Indium; Electrodeposition; Nucleation and growth; Electrolyte additive; Tetrabutylammonium choride

\section{Introduction}

Electrodeposition of indium has been comprehensively investigated on solid electrodes such as platinum, glassy carbon electrode, nickel, tungsten, molybdenum and copper [1-7]. This great interest is due to the practical application of indium, namely, the production of an ultrapure metal with subsequent use in the preparation of various semiconductor alloys. The most complete review of the electroreduction of indium on various electrodes is given in [8,9]. Recently, in the electrodeposition of indium, ionic liquids were used as an electrolyte, which makes it possible to obtain compact coatings of indium and its alloys [10-14]. This effect is explained by the increase of the number of active sites during electrodeposition of indium on tungsten and glassy carbon electrodes [4]. From aqueous chloride electrolytes, high purity indium is obtained, but forms dendritic coatings [15].

Earlier studies $[16,17]$ have established the influence of chloride ions on the electrocrystallization of indium on a glassy carbon electrode, and the limiting stage of electrochemical reduction of indium and the nucleation mechanism were determined. It has been established that as the concentration of chloride ions increases, the nucleation rate increases too. 
To improve the quality of the coatings, it is necessary to add surfactants to the electrolyte, which show have a leveling action in indium electrodeposition. In [18-21], additions of quaternary ammonium salts were used to inhibit dendritic formation during electrodeposition of zinc, copper and silver; these additives showed a high leveling effect. Formation of compact coatings is possible when surfactants are added to the electrolyte. So, in [22,23], for electrodeposition of zinc on carbon steel (AISI 1018), additives of quaternary ammonium compounds were used to obtain compact coatings. Nbenzyltriethylammonium chloride and tetrabutylammonium hydroxide additives inhibit the growth of dendrites and can be used as a leveling additive, whereas in the case of tetraethylammonium hydroxide this effect is negligible [24].

In this paper, we studied the electroreduction of indium on a glassy carbon electrode in the presence of tetrabutylammonium chloride (TBACh) using a rotating disk electrode and chronoamperometry. In addition, the kinetics of the initial stages of electrocrystallization and local deposition of fragments of a new solid phase has been studied. Calculations for the study of nucleation were carried out using threedimensional nucleation models of Scharifker-Hills, Scharifker-Mostany and Mirkin-Nilov-HeermanTarallo. The theoretical calculations used in this work are described in detail in the works of the above authors [25-29].

\section{Experimental}

All electrochemical experiments were carried out in a conventional three-electrode electrochemical cell in a volume of $100 \mathrm{~mL}$ using Autolab $^{\circledR}$ PGSTAT $302 \mathrm{~N}$ and Bio-Logic ${ }^{\circledR}$ VSP 300 potentiostat/galvanostats. A platinum plate (an indium plate in case of long-term chronoamperometry) and an $\mathrm{Ag} / \mathrm{AgCl}\left(\mathrm{Metrohm}^{\circledR}\right)$ were used as the counter and reference electrodes, respectively. The working electrode was GCE produced by Metrohm ${ }^{\circledR}$ with the geometric area of about $0.07 \mathrm{~cm}^{2}$. 
A $2 \mathrm{M} \mathrm{NaCl}$ solution containing $0.05 \mathrm{M} \mathrm{InCl}_{3}$ with $\mathrm{pH} 1.5$ was used as a blank solution. Tetrabutylammonium chloride with different concentrations was then added into blank solution. $\mathrm{InCl}_{3}$ (Sigma Aldrich, 99.99\%) and TBACh (Sigma Aldrich, 99.99\%) were used without further purification. The experiments were performed with variation of the temperature, overpotential and rotation speed. The scan rate was $10 \mathrm{mV} \mathrm{s}^{-1}$. Before each measurement the working electrode was polished and rinsed with distilled water. From the voltammetric study, reduction potentials for chronoamperometric experiments were chosen in order to study the mechanism of nucleation from current transient and then obtain bulk indium deposits with longer deposition times. The chronoamperometric measurements at 35 ${ }^{\circ}$ were chosen because of the optimal temperature of electrochemical refining of indium which is $\sim 40$ ${ }^{\circ} \mathrm{C}$. Voltammetric researches were then conducted in a temperature range of $25-55{ }^{\circ} \mathrm{C}$.

The electrical double layer impedance was measured using an Autolab ${ }^{\circledR}$ PGSTAT $302 \mathrm{~N}$ potentiostat/galvanostat with a FRA $32 \mathrm{M}$ module at the potential of $-1.0 \mathrm{~V}$ in the frequency range of $100 \mathrm{kHz}$ to $210 \mathrm{~Hz}$ at the amplitude of 10 and the system was calibrated using a standard equivalent cell produced by Metrohm. Impedance measurements were carried out in $2 \mathrm{M} \mathrm{NaCl}$ solutions (pH 1.5) without and with $1 \times 10^{-4} \mathrm{M}$ of TBACh. The interpretation of the experimental data of impedance measurements was carried out using the Frumkin - Melik-Gaikazyan (FMG) circuit, which is presented in the work of Laes [30] on the kinetics of tetrabutylammonium ion adsorption on a $\mathrm{Bi}(011)$ plane. A good correlation was obtained between the experimental data and their fitting using this circuit. Criteria for estimating the correlation were such parameters as the $\chi^{2}$ - Chi-square function and $\Delta^{2}$ - weighted sum of squares.

Scanning Electron Microscopy (SEM Philips XL-30 FEG) was used to study the morphology of the indium deposits.

\section{Results and discussion}




\subsection{Kinetics of indium electroreduction}

The current-time curves of indium electroreduction from the following aqueous acidic chloride solutions with and without TBACh at the cathodic potential $\mathrm{E}=-0.95 \mathrm{~V}$ are shown in Fig. 1. At this potential, all current can be attributed to indium deposition, given the high overvoltage of hydrogen reduction on indium $\left(j_{0}=8 \times 10^{-12} \mathrm{~A} \mathrm{~cm}^{-2}\right)[31]$.

$<$ Figure 1>

Fig. 1 shows the limiting diffusion current at small times $(1500 \mathrm{~s})$ of the $\mathrm{I}-\mathrm{t}$ curve. It can be seen from Fig. 1 (curves 1,3) that at large times (3000-7500s), there is a significant increase in the cathodic deposition current of indium for the blank electrolyte and blank solution with $10^{-3} \mathrm{M}$ TBACh (from about 7.2 to $20.1 \mathrm{~mA}$ ). Since any rise in cathodic current during a potentiostatic electrodeposition is assumed to be due to an increase in true electrode surface area, the variation in current versus time at constant applied potential reflects the change in surface morphology (roughness, often dendritic growth) with a high sensitivity [18]. Thus, in this manner, the efficiency of morphology-controlling additive and its concentration can be readily assessed by their effect on the current [32]. The addition of $10^{-4} \mathrm{M}$ TBACh in the electrolyte of electrodeposition produces flat current-time responses (curve 2). If the concentration of TBACh increases 10-fold, no effect is observed (curve 3). Visual observation of the sample in blank solution after the experiment showed needle - shaped dendritic indium. Same observations were made for samples obtained in the presence of $10^{-3} \mathrm{M}$ TBACh deposits. But with addition of $10^{-4} \mathrm{M}$ TBACh in the electrolyte, the current remains constant, indicating the inhibitory effect on formation of dendrites during indium electrodeposition. This is also confirmed by visual observation.

To explain the inhibitory effect of TBACh on the process of dendritic formation during electrodeposition of indium, the kinetics of electroreduction and phase-formation of indium on a GCE was studied.

Electroreduction of indium from chloride solutions can be represented as follows: 


$$
\left[\mathrm{InCl}_{n}\right]^{-n+3}+3 \bar{e} \rightarrow \mathrm{In}^{0}+n C l^{-}
$$

Fig. 2 shows cyclic voltammograms of the discharge-ionization of indium on a glassy carbon electrode from a chloride electrolyte of the following composition $0.05 \mathrm{M} \mathrm{InCl}_{3}+2 \mathrm{M} \mathrm{NaCl}$. The reduction starts at $\mathrm{E}=-0.76 \mathrm{~V}$ with an increase in cathodic current, followed by a limiting diffusion current at $-0.83 \mathrm{~V}$.

Varying the speed of rotation of the disk electrode allows establishing the limiting stage of the electrode process. The values of the limiting cathode currents grow with the increasing rotation speed. The growth of the area of the anode peak at different rotation rates is explained by the increase in the mass of the deposited indium. To determine the diffusion coefficient of $\mathrm{In}^{3+}$ ions, the dependence of the limiting cathode currents $(j$ l.c. $)$ on the square root of the angular velocity of rotation $\left(\omega^{1 / 2}\right)$ was used. The diffusion coefficient of $\operatorname{In}^{3+}$ ions was calculated using Levich equation on the basis of the dependence of the limiting cathode currents $\left(j_{l . c}\right)$ on the square root of the angular velocity of rotation $\left(\omega^{1 / 2}\right)($ Fig. 2 . Inset) It was found that the rate-determining stage of the electroreduction of indium on a glassy carbon electrode is diffusion.

$<$ Figure 2>

The above presented dependence (Fig. 2. Inset) is characterized by a high correlation coefficient (in all cases $\mathrm{R}^{2}>0.99$ ), which makes it possible to calculate the diffusion coefficient of $\mathrm{In}^{3+}$ ions at different temperatures (Table 1). As the temperature increases, an increase in the limiting cathode currents is observed (Fig. 3), which is associated with an increase in the diffusion coefficient $\left(D_{I n^{3+}}\right)$, obeying the Arrhenius equation (Fig. 3. Inset). 
The effect of TBACh on the discharge-ionization of indium is shown in Fig. 4 (A). Adsorption of surfactants on the surface of the electrode can change the rate of electrode reactions within wide limits. In this case, the slowdown is most often observed. One can see a significant decrease in the cathodic currents in the presence of the additive, and a decrease in the slope angle of the $j-E$ curve is observed at the anode branch of the cyclic voltammogram, which is associated with an increase in the polarization resistance. Without TBACh it is observed that the limiting diffusion current is the same for reverse and forward course of the voltammogram. But addition of TBACh shows a significant difference between the forward and reverse course. This difference could be due to the different adsorption of tetrabutylammonium ions on the glassy carbon electrode and on the surface covered with indium. One can see the decrease in the rate of the process in the region of high surface coverages of glassy carbon electrode with adsorbate (more negative than $-1.1 \mathrm{~V}$ ) and the influence of surface nature on limiting cathode current is insignificant. The difference in the cathodic current density in the potential range from $-0.64 \mathrm{~V}$ to $-0.9 \mathrm{~V}$ in both cases (curve 1 and curve 2 ) is related to the nucleation overpotential. The given dependence ("current crossover") is typical for the processes of 3D electrodeposition of metals. In addition, the observed shift in the potential of the initiation of deposition $\left(E_{n}\right.$ is the nucleation potential) is due to the inhibition of the electroreduction process of indium (Fig. 4A). Adsorption, which is preferable at fractures, blocks them, which leads to a reduction in the number of growth sites and the formation of new nuclei and clusters on a flat surface regardless of the existing steps [33].

$<$ Figure 4>

The adsorption of TBACh on the surface of the glassy carbon electrode is confirmed by impedance measurements (Fig. 4 (B)). The impedance spectroscopy diagrams are shown in Fig. 4 (B). The data have been perfectly fitted using a Frumkin-Melik-Gaykazyan circuit, where $R_{\mathrm{el}}$ and $\mathrm{C}_{\mathrm{dl}}$ are respectively the resistance of solution and the double layer capacitance and $\mathrm{W}$ is the Warburg element that describes the diffusion of species. According to classical models, this circuit includes an additional capacitance 
$\left(\mathrm{C}_{\mathrm{ad}}\right)$ related to adsorption of surfactant.

From the figure (Fig. 4 (B) inset), a significant reduction of the double layer capacitance is observed in electrolyte containing TBACh. This indicates clearly the adsorption of TBACh on the electrode surface in the range of the electrodeposition potentials of indium. With a TBACh concentration of $10^{-4} \mathrm{M}$, the capacitance is $\sim 7.4 \mu \mathrm{F} \mathrm{cm}{ }^{-2}$.

B.B. Damaskin and al [34], also studied the adsorption behavior of tetrabutylammonium iodide (TBAI) on polycrystalline indium in a solution of $\mathrm{Na}_{2} \mathrm{SO}_{4}$. They pointed out from the capacitance measurements that with an addition of $10^{-3} \mathrm{M}$ TBAI, the double layer capacitance is $\sim 10 \mu \mathrm{F} \mathrm{cm}^{-2}$. This decrease of the double layer capacitance means a decrease in the surface charge of the electrode and an inhibition of the process. In this case, adsorbed molecules or ions can directly participate in all stages of the electrode process, including charge transfer. The influence of adsorbate is described by the amount of adsorbed ions coverage $-\theta$. This function $f(\theta)$ describes not only the partial blocking of the surface by the adsorbate, but also the overcoming of the additional potential barrier $\Delta G(\theta)$ by the depolarizer, which includes a quantity reflecting interactions in the adsorbed layer such as the bridging effect. In addition, the above function describes the change in the $\psi^{\prime}$ - potential in the presence of adsorbed ions.

In our case, the electroreduction of In occurs via the electron bridge mechanism as a result of adsorption of chloride ions on indium ad-atoms and the further interaction of these ions with $\left[\mathrm{InCl}_{2}\left(\mathrm{H}_{2} \mathrm{O}\right)_{\mathrm{n}}\right]^{+}$ions from the solution. The electron bridge mechanism of indium electroreduction was investigated by A.G. Munoz, S.B. Saidman and J.B. Bessone in the work [16]. The change in the surface of the glassy carbon electrode on the reverse course of the current-voltage curve leads to the appearance above-mentioned effect and to a change in the surface coverage $(\theta)$. This apparently explains the difference in the limiting diffusion current of indium electroreduction in the forward and reverse course of the potential scan (Fig. 4A, curve 2). 
Similarly, it can be seen from Fig. 4 (A) that in the presence of the $\mathrm{TBA}^{+}$ion, with decreasing potential, the cathode current density decreases gradually, and at a potential of $-1.2 \mathrm{~V}$ it approaches zero. This effect can be explained by the surface coverage $(\theta)$ by adsorbed $\mathrm{TBA}^{+}$ions. Shifting the potential into the negative region can increase $\theta$ and the repulsive interaction energy between the $\left[\mathrm{N}_{(}\left(\mathrm{C}_{4} \mathrm{H}_{9}\right)_{4}\right]^{+}$and $\left[\operatorname{In}\left(\mathrm{H}_{2} \mathrm{O}\right)_{\mathrm{n}}\right]^{3+}$ ions, thereby inhibiting the electrode process. From the literature $[35,36]$ it is known that the change in the free energy of the repulsive interaction depends nonlinearly on the surface coverage, and it increases sharply at $\theta>0.6$. The nature of the interaction of adsorbed $\mathrm{TBA}^{+}$ions and the depolarizer is very complex, and deserves special study.

Analogous voltammetric measurements and calculations have been performed for the determination $D_{I^{3+}}$ in the presence of TBACh. Fig. 5 shows the CVA at different temperatures and the rotation speed of the electrode.

$<$ Figure 5>

To assess the correctness of the determination of the diffusion coefficient of indium ions under the investigated conditions by the RDE method, the universal Stokes-Einstein equation was used, which is applicable both for organic and for aqueous media.

$$
D_{I n^{3+}}=\frac{k T}{6 \pi \eta a}
$$

Here: $D_{I n^{3+}}$ is the diffusion coefficient of In (III) ions $\left(\mathrm{m}^{2} \mathrm{~s}^{-1}\right) ; k$ is the Boltzmann constant $\left(1.381 \times 10^{-10}\right.$ $\left.\mathrm{J} \mathrm{K}^{-1}\right), \eta$ is the dynamic viscosity of the solution ( $\mathrm{Pa} \mathrm{s}$ ), $a$ is the radius of the ion $(\mathrm{m})$, and $T$ is the absolute temperature $(\mathrm{K})$.

It is known from [37-39] that in aqueous solutions, the hydrated indium ion - $\mathrm{In}\left(\mathrm{H}_{2} \mathrm{O}\right)_{6}{ }^{3+}$ has a regular octahedral shape and a radius of $21.4 \mathrm{~nm}$. The values $\eta$ of the dynamic viscosity of the solution were 
taken from the literature [40]. The possibility of applying the Stokes-Einstein model to calculate the theoretical radius of indium ions from the experimentally determined values of the diffusion coefficient is shown in [41]. The values of the diffusion coefficient of $\mathrm{In}^{3+}$, calculated from equation (1) and experimentally found, and the activation energy $\left(E_{a}\right)$ are presented in Table 1.

\section{$<$ Table 1>}

The is a slight difference in the calculated and experimentally determined values which could be due to the lack of consideration of the solvation process and various interactions in solution with the participation of background electrolyte components, in obtaining the calculated values of the diffusion coefficient. Similar results were obtained by Andrew P. Abbott and his colleagues in [42]. Taking into account all of the above, as well as the simplified nature of the model, it can be noted that the difference in the values of the indium ion diffusion coefficient, calculated and experimentally determined, is entirely permissible.

To confirm the reliability of the values $D_{I n^{3+}}$ obtained by the RDE method, we found the diffusion coefficient of $\mathrm{In}^{3+}$ ions at $35^{\circ} \mathrm{C}$ from chronoamperometric measurements based on the Cottrell equation. Its numerical value was $6.35 \times 10^{-6} \mathrm{~cm}^{2} \mathrm{~s}^{-1}$, which agrees well with the result obtained by the RDE method $\left(6.14 \times 10^{-6} \mathrm{~cm}^{2} \mathrm{~s}^{-1}\right)$.

Thus, it is established from the results obtained that the electroreduction of indium on a glassy carbon electrode proceeds in a diffusion mode. The addition of $10^{-4} \mathrm{M}$ TBACh leads to a shift in the potential of the onset of indium deposition into the region of negative potentials and the inhibition of the cathodic process. This is confirmed by a significant increase in the activation energy of the process (by $17 \mathrm{~kJ}$ $\left.\mathrm{mol}^{-1}\right)$. 


\subsection{Nucleation studies}

In order to determine the kinetic parameters of electrocrystallization and the type of nucleation, potentiostatic transients for the electrodeposition of indium on $\mathrm{GC}$ electrode in $0.05 \mathrm{M} \mathrm{InCl} \mathrm{I}_{3}$ containing solutions were obtained. It can be seen from the chronoamperograms that, at a potential of $-0.65 \mathrm{~V}$, indium electrodeposition is not observed (Fig. 6 A, B). At a potential of $-0.70 \mathrm{~V}$, electroreduction of $\mathrm{In}^{3+}$ ions occurs and the current maxima are observed $\left(j_{\max }=-6.3 \mathrm{~mA} \mathrm{~cm}{ }^{-2} ; t_{\max }=10.61 \mathrm{~s}\right)$, which is associated with the overlapping of the diffusion zones of individual crystallites and hemispherical masstransfer gives way to linear mass-transfer to a effectively planar surface. The further course of the current transients is explained by the diffusion limitation. Additions of tetrabutylammonium to deposition electrolyte significantly shift the chronoamperogram maxima to the region of small times $\left(t_{\max }=0.93 \mathrm{~s} ; j_{\max }=-23.3 \mathrm{~mA} \mathrm{~cm}^{-2}\right)$.

$<$ Figure 6>

The shape of the experimental potentiostatic transients in the non-dimensional coordinates $\left(\left(j / j_{\max }\right)^{2}-\right.$ $t / t_{\max }$ ) depends on the nature of the rate-determining stage and the type of nucleation. In the case of diffusion-controlled processes, the approach to analyzing the above transients has been developed by B.R. Scharifker and G.J. Hills. Experimental transients are compared in Fig. 7 A, B to transients calculated according to the Scharifker-Hills ( $\mathrm{SH}$ ) model for instantaneous and progressive threedimensional nucleation.

\footnotetext{
$<$ Figure 7>
}

The experimental curves obtained without tetrabutylammonium chloride are in good agreement with a 3D progressive nucleation (Fig. 7A). Same type of nucleation has been pointed out with TBACh additives. 
The stationary nucleation rate $-A N_{\infty}$ and saturation nucleus density $-N_{\text {sat }}$ for $3 \mathrm{D}$ progressive nucleation with diffusion control are calculated from the current maxima of the potentiostatic transients, according to the well-known equations [29]. In the SH model, the estimation of the nucleation parameters is based only on one point $\left(t_{\max }\right.$ and $\left.j_{\max }\right)$. For a more accurate assessment of the kinetic parameters of indium crystallization on glassy carbon, more appropriate models have been used, such as the Scharifker-Mostany (SM) model and the Mirkin-Nilov-Heerman-Tarallo (MNHT) model. According to the literature [43], the accuracy of the SM model depends on the time interval, and this model well describes theoretical dependence of $j$ vs. $t$ just in the limit of a longer time. The MNHT model includes a correction to the SM model for short periods of time. The values of the stationary nucleation rate, obtained by fitting the theoretically calculated $j_{c}-t$ curve (Fig. 8) using the SM and MNHT models are presented in Table 2.

$<$ Figure 8>

$<$ Table 2>

As can be seen from Table 2 and Fig. 9, in case of indium electrodeposition on a glassy carbon electrode as the polarization increases, the stationary nucleation rate and the saturation nucleus density increase. At a potential of $-0.7 \mathrm{~V}$ in a blank electrolyte, the stationary nucleation rate calculated from the $\mathrm{SH}$ model was $1.25 \times 10^{4} \mathrm{~cm}^{-2} \mathrm{~s}^{-1}$, and at a potential of $-0.95 \mathrm{~V}$ the nucleation rate is $2.76 \times 10^{7} \mathrm{~cm}^{-2} \mathrm{~s}^{-1}$. This effect is enhanced in the presence of tetrabutylammonium additives. Thus, at a potential of $-0.95 \mathrm{~V}$ in the presence of TBACh, the value $A N_{\infty}$ increases from $2.76 \times 10^{7} \mathrm{~cm}^{-2} \mathrm{~s}^{-1}$ to $1.05 \times 10^{8} \mathrm{~cm}^{-2} \mathrm{~s}^{-1}$. From the values $N_{\text {sat }}$ found the average radius of grains of electrodeposited indium was calculated from equation 7 in [4] (Fig. 9). 
$<$ Figure 9>

Increase in overvoltage significantly reduces the average radius grains of the cathode deposit in the absence of TBACh. With an increase in the overvoltage from $60 \mathrm{mV}$ to $310 \mathrm{mV}$, the average grain radius decreases from $65.2 \mu \mathrm{m}$ to $9.5 \mu \mathrm{m}$, respectively. Additions of tetrabutylammonium even with small overvoltages lead to the formation of finely dispersed deposits of indium. At overvoltage of 310 $\mathrm{mV}$ in the presence of TBACh, a deposit with a grain size of $5.7 \mu \mathrm{m}$ is formed. In the presence of $10^{-4} \mathrm{M}$ TBACh in the electrolyte, the difference in the grain size with increasing overvoltage decreases.

To confirm these calculations, the morphology of indium coatings obtained in an electrolyte containing $10^{-4}$ M TBACh was observed by Scanning Electron Microscopy (Fig. 10), and EDX analysis results are shown in inset. For each deposit, EDX analysis confirmed the presence of indium metal on the glassy carbon substrate.

$<$ Figure 10>

The comparison of the morphology of indium coatings in electrolytes with and without tetrabutylammonium chloride shows that in presence of additive, the grains have a smaller radius. This is in good agreement with the previously calculated average radii of grains and confirms the levelling effect of TBACh, leading to the formation of dense and uniform coatings.

\section{Conclusion}

In order to obtain dense, uniform indium deposits during electrorefining, indium was deposited on a glassy carbon electrode in chloride electrolytes containing tetrabutylammonium chloride. It has been established that small additions of tetrabutylammonium in the electrolyte cause a leveling effect. 
The diffusive nature of the rate-determining stage of electroreduction of indium on a glassy carbon electrode from chloride electrolytes by the method of a rotating disk electrode has been established. The diffusion coefficient of $\mathrm{In}^{3+}$ ions was determined in chloride electrolytes with and without TBACh. In an electrolyte containing $10^{-4} \mathrm{M}$ TBACh, the diffusion coefficient decrease and the activation energy of the process increases by $17 \mathrm{~kJ} \mathrm{~mol}^{-1}$, indicating an inhibition of the electrode process.

The experimentally determined diffusion coefficient is in agreement with that theoretically calculated from Stokes-Einstein equations.

From chronoamperometric measurements a three-dimensional progressing nucleation with diffusion control has been established, in agreement to Scharifker-Hills model. The presence of tetrabutylammonium increases the nucleation rate and the saturation density of the number of active centers. This leads to a decrease in the average grain radius of electrodeposited indium at an overvoltage of $310 \mathrm{mV}$ in $10^{-4} \mathrm{M}$ TBACh electrolyte, from $12.5 \mu \mathrm{m}$ to $5.7 \mu \mathrm{m}$. The results of SEM analysis confirm the formation of compact coatings of indium.

\section{Acknowledgement}

Authors gratefully acknowledges the Ministry of Education and Science of the Republic of Kazakhstan for financial support through grant number No. 1580 / GF4.

\section{References}

[1] Q. Huang, K. Reuter, S. Amhed, L. Deligianni, L.T. Romankiw, S. Jaime, P.-P. Grand, V. Charrier, Electrodeposition of Indium on Copper for CIS and CIGS Solar Cell Applications, J. Electrochem. Soc. 158 (2011) D57. doi:10.1149/1.3518440.

[2] J.S.-Y. Liu, Electrochemical Study of the Properties of Indium in Room Temperature Chloroaluminate Molten Salts, J. Electrochem. Soc. 144 (1997) 140. doi:10.1149/1.1837376.

[3] R.C. Valderrama, M. Miranda-Hernández, P.J. Sebastian, A.L. Ocampo, Electrodeposition of indium onto $\mathrm{Mo} / \mathrm{Cu}$ for the deposition of $\mathrm{Cu}(\mathrm{In}, \mathrm{Ga}) \mathrm{Se} 2$ thin films, Electrochim. Acta. 53 (2008) 3714-3721. doi:10.1016/j.electacta.2007.11.069.

[4] M.-H. Yang, I.-W. Sun, Electrochemical Study of Indium in a Water-Stable 1-Ethyl-3Methylimidazolium Chloride/Tetrafluoroborate Room Temperature Ionic Liquid, J. Chinese 
Chem. Soc. 51 (2004) 253-260. doi:10.1002/jccs.200400040.

[5] Y. Chung, C.-W. Lee, Nucleation Process of Indium on a Copper Electrode, J. Electrochem. Sci. Technol. 4 (2013) 93-101. doi:10.5229/JECST.2013.4.3.93.

[6] C.M. Pettit, J.E. Garland, N.R. Etukudo, K.A. Assiongbon, S.B. Emery, D. Roy, Electrodeposition of indium on molybdenum studied with optical second harmonic generation and electrochemical impedance spectroscopy, Appl. Surf. Sci. 202 (2002) 33-46. doi:10.1016/S0169-4332(02)00798-5.

[7] G. Rakhymbay, M.K. Nauryzbayev, B.D. Burkitbayeva, A.M. Argimbaeva, R. Jumanova, A.P. Kurbatov, M. Eyraud, P. Knauth, F. Vacandio, Electrochemical deposition of indium: nucleation mode and diffusional limitation, Russ. J. Electrochem. 52 (2016) 99-105. doi:10.1134/S1023193516020087.

[8] Y.H. Chung, C.W. Lee, Electrochemical behaviors of Indium, J. Electrochem. Sci. Technol. 3 (2012) 1-13. doi:10.5229/jecst.2012.3.1.1.

[9] R. Piercy, N.A. Hampson, The electrochemistry of indium, J. Appl. Electrochem. 5 (1975) 115. doi:10.1007/BF00625955.

[10] J. Estager, P. Nockemann, K.R. Seddon, G. Srinivasan, M. Swadźba-Kwaśny, Electrochemical synthesis of indium(0) nanoparticles in haloindate(III) ionic liquids, ChemSusChem. 5 (2012) 117-124. doi:10.1002/cssc.201100331.

[11] Y. Traore, S. Legeai, S. Diliberto, G. Arrachart, S. Pellet-Rostaing, M. Draye, New insight into indium electrochemistry in a Tf2N-based room-temperature ionic liquid, Electrochim. Acta. 58 (2011) 532-540. doi:10.1016/j.electacta.2011.09.085.

[12] Y.T. Hsieh, Y.C. Chen, I.W. Sun, Electrodeposition of Stoichiometric Indium Antimonide from Room-Temperature Ionic Liquid 1-Butyl-1-Methylpyrrolidinium Dicyanamide, ChemElectroChem. 3 (2016) 638-643. doi:10.1002/celc.201500522.

[13] S.I. Hsiu, C.C. Tai, I.W. Sun, Electrodeposition of palladium-indium from 1-ethyl-3methylimidazolium chloride tetrafluoroborate ionic liquid, Electrochim. Acta. 51 (2006) 26072613. doi:10.1016/j.electacta.2005.07.042.

[14] S. Zein El Abedin, A.Y. Saad, H.K. Farag, N. Borisenko, Q.X. Liu, F. Endres, Electrodeposition of selenium, indium and copper in an air- and water-stable ionic liquid at variable temperatures, Electrochim. Acta. 52 (2007) 2746-2754. doi:10.1016/j.electacta.2006.08.064.

[15] L.F. Kozin, S.N. Nagibin, E.I. Chabanenko, Electrochemical refining of indium in aqueous solutions with solid electrodes, Vysok. Veshchestva. 29 (1996) 30-46. https://inis.iaea.org/search/search.aspx?orig_q=RN:29005230.

[16] A.G. Muñoz, S.B. Saidman, J.B. Bessone, Electrodeposition of Indium onto Vitreous Carbon from Acid Chloride Solutions, J. Electrochem. Soc. 146 (1999) 2123. doi:10.1149/1.1391902.

[17] G. Gunawardena, D. Pletcher, A. Razaq, The electrodeposition of indium onto vitreous carbon from acidic chloride media, J. Electroanal. Chem. Interfacial Electrochem. 164 (1984) 363-367. doi:10.1016/S0022-0728(84)80218-1.

[18] Y. Wen, T. Wang, J. Cheng, J. Pan, G. Cao, Y. Yang, Lead ion and tetrabutylammonium bromide as inhibitors of the growth of spongy zinc in single flow zinc/nickel batteries, Electrochim. Acta. 59 (2012) 64-68. doi:10.1016/j.electacta.2011.10.042.

[19] C. Mele, B. Bozzini, Silver electrodeposition from water-acetonitrile mixed solvents in the presence of tetrabutylammonium perchlorate : PPart II-A SERS study of acetonitrile reactivity and tetrabutylammonium adsorption, J. Solid State Electrochem. 13 (2009) 1553-1559. doi:10.1007/s10008-008-0724-y.

[20] C. Mele, S. Rondinini, L. D’Urzo, V. Romanello, E. Tondo, A. Minguzzi, A. Vertova, B. Bozzini, Silver electrodeposition from water-acetonitrile mixed solvents and mixed electrolytes in the presence of tetrabutylammonium perchlorate. Part I-electrochemical nucleation on glassy carbon electrode, J. Solid State Electrochem. 13 (2009) 1577-1584. doi:10.1007/s10008-0080732-y.

[21] Q. Zhang, X. Yu, Y. Hua, W. Xue, The effect of quaternary ammonium-based ionic liquids on copper electrodeposition from acidic sulfate electrolyte, J. Appl. Electrochem. 45 (2015) 79-86. 
doi:10.1007/s10800-014-0774-z.

[22] P.K. Leung, C. Ponce-De-León, C.T.J. Low, F.C. Walsh, Zinc deposition and dissolution in methanesulfonic acid onto a carbon composite electrode as the negative electrode reactions in a hybrid redox flow battery, Electrochim. Acta. 56 (2011) 6536-6546. doi:10.1016/j.electacta.2011.04.111.

[23] J.M. Wang, L. Zhang, C. Zhang, J.Q. Zhang, Effects of bismuth ion and tetrabutylammonium bromide on the dendritic growth of zinc in alkaline zincate solutions, J. Power Sources. 102 (2001) 139-143. doi:10.1016/S0378-7753(01)00789-3.

[24] J.L. Ortiz-Aparicio, Y. Meas, T.W. Chapman, G. Trejo, R. Ortega, E. Chainet, Electrodeposition of zinc in the presence of quaternary ammonium compounds from alkaline chloride bath, J. Appl. Electrochem. 45 (2015) 67-78. doi:10.1007/s10800-014-0777-9.

[25] M.V. Mirkin, A.P. Nilov, Three-dimensional nucleation and growth under controlled potential, J. Electroanal. Chem. Interfacial Electrochem. 283 (1990) 35-51. doi:10.1016/00220728(90)87377-V.

[26] B.R. Scharifker, J. Mostany, Three-dimensional nucleation with diffusion controlled growth, J. Electroanal. Chem. Interfacial Electrochem. 177 (1984) 13-23. doi:10.1016/00220728(84)80207-7.

[27] A. Milchev, L. Heerman, Electrochemical nucleation and growth of nano- and microparticles: Some theoretical and experimental aspects, Electrochim. Acta. 48 (2003) 2903-2913. doi:10.1016/S0013-4686(03)00355-4.

[28] L. Heerman, A. Tarallo, Theory of the chronoamperometric transient for electrochemical nucleation with diffusion-controlled growth, J. Electroanal. Chem. 470 (1999) 70-76. doi:10.1016/S0022-0728(99)00221-1.

[29] B. Scharifker, G. Hills, Theoretical and experimental studies of multiple nucleation, Electrochim. Acta. 28 (1983) 879-889. doi:10.1016/0013-4686(83)85163-9.

[30] K. Laes, H. Kasuk, G. Nurk, M. Väärtnõu, K. Lust, A. Jänes, E. Lust, Adsorption kinetics of tetrabutylammonium cations on $\mathrm{Bi}\left(011^{-}\right)$plane, J. Electroanal. Chem. 569 (2004) 241-256. doi:10.1016/j.jelechem.2004.03.007.

[31] B.. Damaskin, O.A. Petriy, Z.. Tsirlina, Electrochemistry, 2nd ed., Khimiya, KolosS, Moskow, 2006.

[32] G.D. Wilcox, P.J. Mitchell, Electrolyte additives for zinc-anoded secondary cells. I. Brighteners, levellers and complexants, J. Power Sources. 28 (1989) 345-359.

[33] Y.D. Gamburg, G. Zangari, Theory and Practice of Metal Electrodeposition, Springer, New York, 2011. doi:10.1007/978-1-4419-9669-5.

[34] A.P. Korotkov, B.B. Damaskin, Tetrabutylammonium ion adsorption on indium electrodes, Sov. Electrochem. 22 (1986) 257-259.

https://apps.webofknowledge.com/full_record.do?product=WOS\&search_mode=GeneralSearch \&qid=1\&SID=C2chV5jfhPlAr5pc2jh\&page $=1 \&$ doc $=1$.

[35] B.N. Afanas'ev, Influence of ions of surface active substance on the kinetics of electrochemical reduction of ions and neutral molecules, Sov. Electrochem. 22 (1986) 170.

[36] V.S. Krylov, B.B. Damaskin, V.A. Kir'yanov, The Present State and Problems of the Theory of the Kinetics of Electrode Reactions Accompanied by the Adsorption of Inactive Substances and Reagents, Russ. Chem. Rev. 55 (1986) 706-720. doi:10.1070/RC1986v055n08ABEH003217.

[37] P. Lindqvist-Reis, Structure of solvated metal ions: Solution and crystal structure of gallium, indium, scandium, yttrium, lanthanum and calcium ions with water and non-aqueous oxygen donor solvents, Royal Institute of Technology, 2000. http://kth.divaportal.org/smash/record.jsf?pid=diva2\%3A8740\&dswid=2213.

[38] P. Lindqvist-Reis, A. Munoz-Paez, S. Diaz-Moreno, S. Pattanaik, I. Persson, M. Sandström, The Structure of the Hydrated Gallium(III), Indium(III), and Chromium(III) Ions in Aqueous Solution. A Large Angle X-ray Scattering and EXAFS Study, Inorg Chem. 37 (1998) 66756683. doi:10.1021/ic980750y.

[39] I. Persson, Hydrated metal ions in aqueous solution: How regular are their structures?, Pure 
Appl. Chem. 82 (2010) 1901-1917. doi:10.1351/PAC-CON-09-10-22.

[40] J. Kestin, E.H. Khalifa, R.J. Correia, Tables of the Dynamic and Kinematic Viscosity of Aqueous KCl Solutions, J. Phys. Chem. Ref. Data. 10 (1981) 57-70.

[41] A.A. Kityk, D.A. Shaiderov, E.A. Vasil'eva, V.S. Protsenko, F.I. Danilov, Choline chloride based ionic liquids containing nickel chloride: Physicochemical properties and kinetics of Ni(II) electroreduction, Electrochim. Acta. 245 (2017) 133-145. doi:10.1016/j.electacta.2017.05.144.

[42] A.P. Abbott, K. El Ttaib, G. Frisch, K.J. McKenzie, K.S. Ryder, Electrodeposition of copper composites from deep eutectic solvents based on choline chloride, Phys. Chem. Chem. Phys. 11 (2009) 4269. doi:10.1039/b817881j.

[43] J.T. Matsushima, L.C.D. Santos, A.B. Couto, M.R. Baldan, N.G. Ferreira, Electrodeposition of $\mathrm{Cu}$ Nanoparticles on BDD Electrodes: Reactions and Nucleation Mechanism, J. Electrochem. Soc. 159 (2012) D246. doi:10.1149/2.093204jes. 

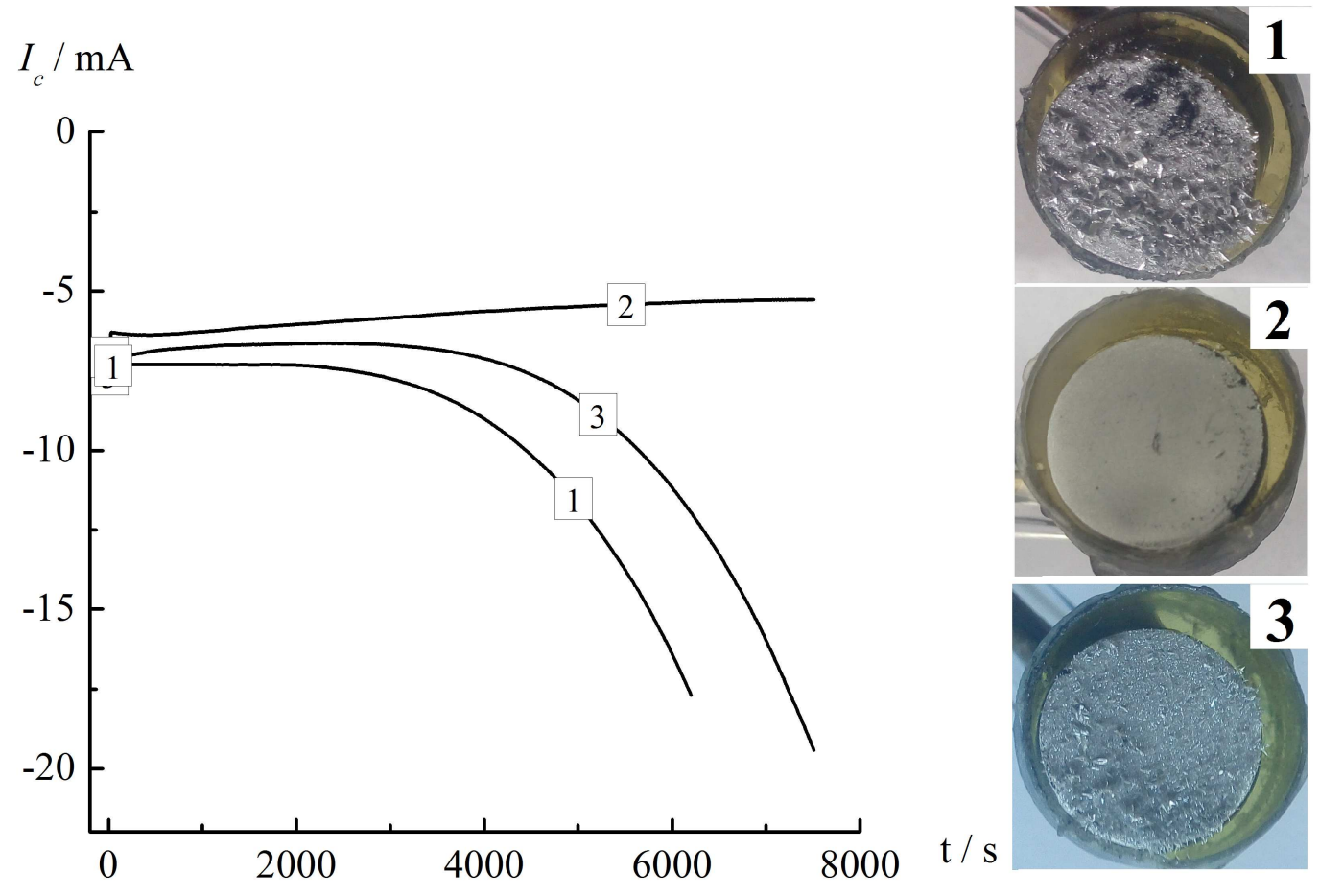

Fig.1 Current - time curves at a constant applied potential - $0.95 \mathrm{~V}$ vs. $\mathrm{Ag} / \mathrm{AgCl}$ for electrodeposition of indium in a blank electrolyte (1): $0.05 \mathrm{M} \mathrm{InCl}_{3}+2 \mathrm{M} \mathrm{NaCl}$; with $10^{-4} \mathrm{M}$ TBACh (2); with $10^{-3} \mathrm{M}$ TBACh (3), at $35^{\circ} \mathrm{C}$. Inset: images for indium coatings after electrolysis. 


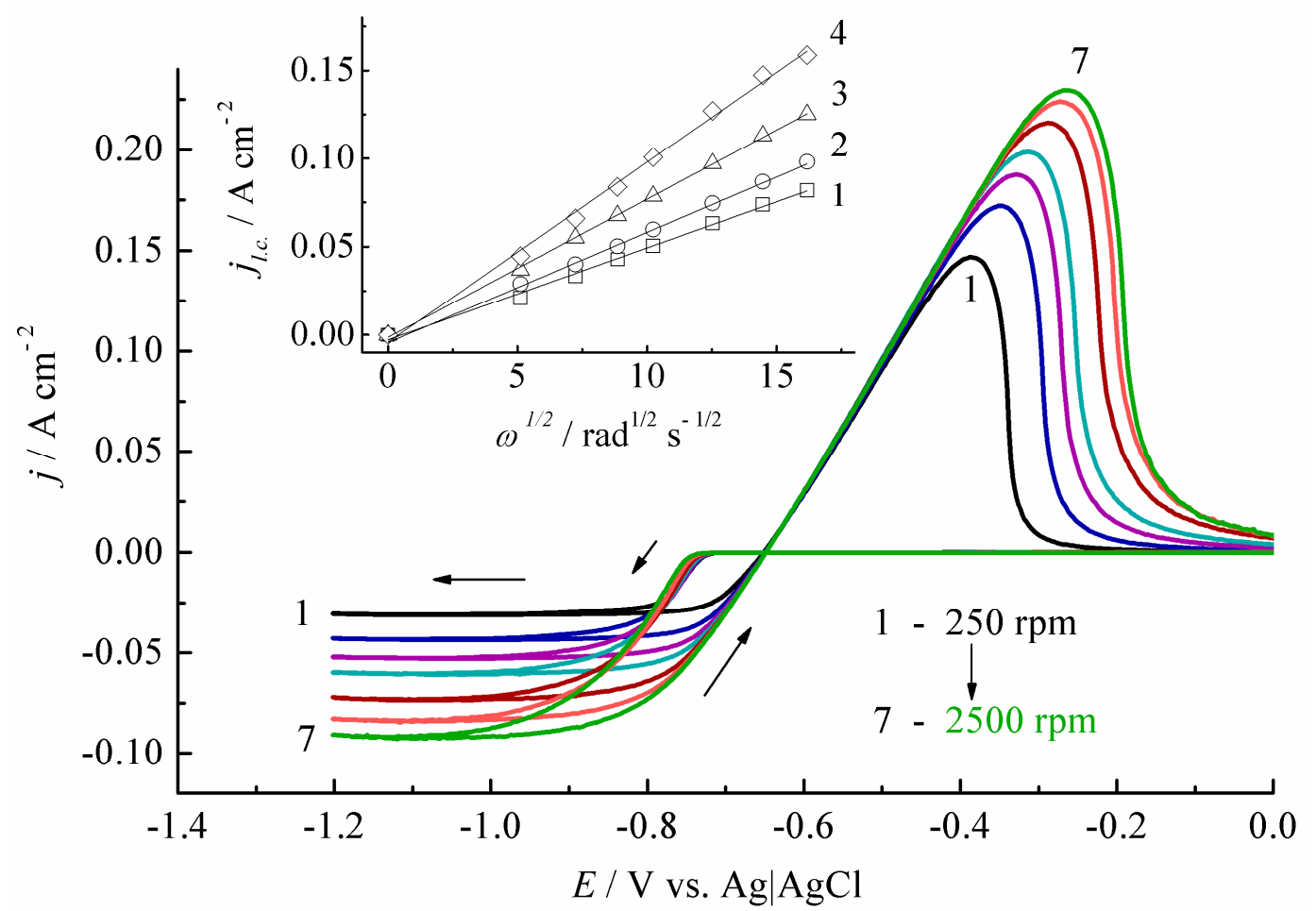

Fig. 2 Cyclic voltammograms obtained at $25^{\circ} \mathrm{C}$ on GC electrode in $0.05 \mathrm{M} \mathrm{InCl}_{3}+2 \mathrm{M} \mathrm{NaCl}$ solution for various rotating rates $(250,500,750,1000,1500,2000$ and $2500 \mathrm{rpm})$. Scan rate of $10 \mathrm{mV} \mathrm{s}^{-1}$. Inset: Levich plot performed at various temperatures: $1-25^{\circ} \mathrm{C} ; 2-35^{\circ} \mathrm{C} ; 3-45^{\circ} \mathrm{C} ; 4$ $-55^{\circ} \mathrm{C}$. 


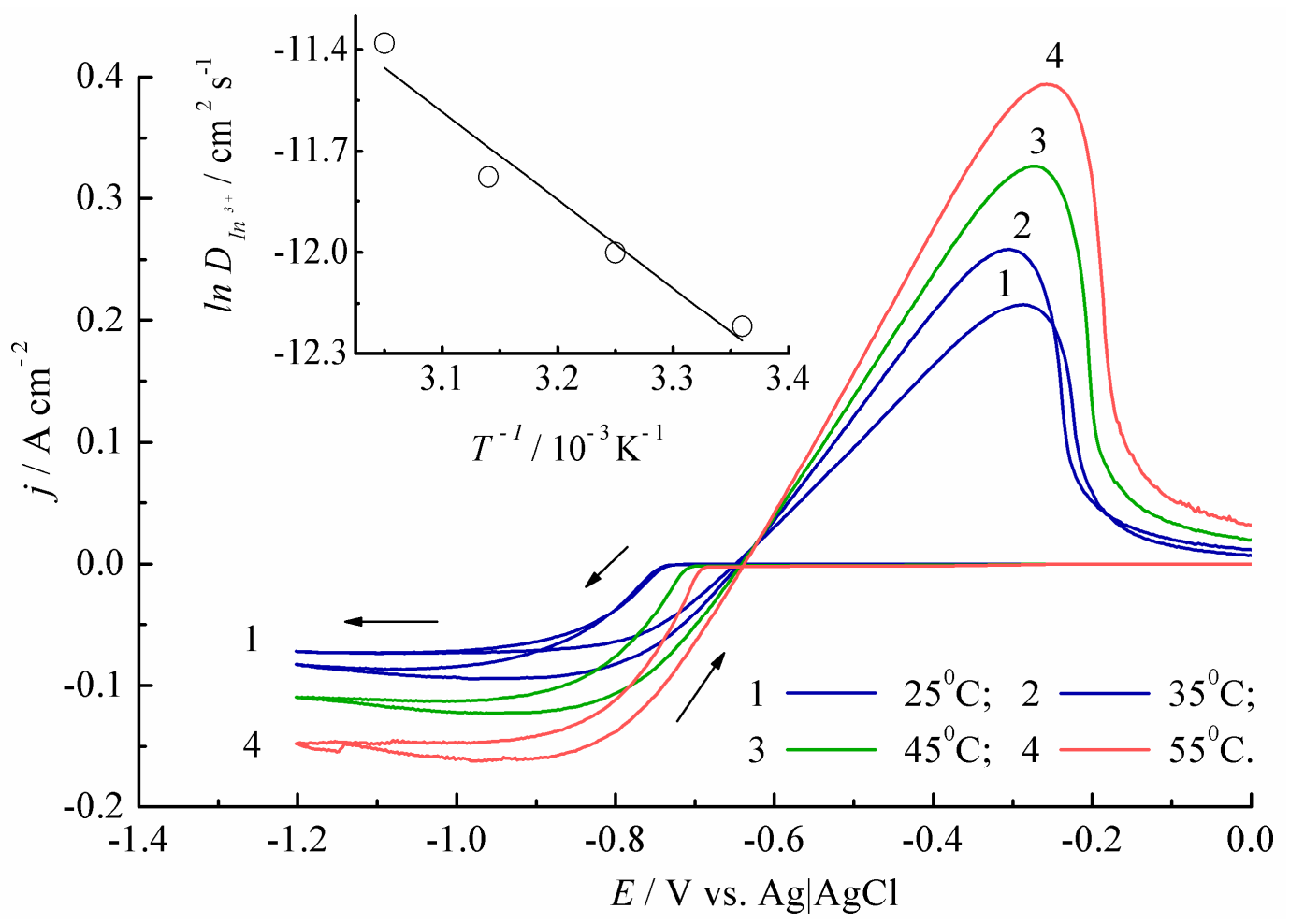

Fig. 3 Cyclic voltammograms obtained at the rotation rate $2000 \mathrm{rpm}$ on GC electrode in $0.05 \mathrm{M}$ $\mathrm{InCl}_{3}+2 \mathrm{M} \mathrm{NaCl}$ solution for various temperatures. Scan rate of $10 \mathrm{mV} \mathrm{s}^{-1}$. Inset: evolution of $D_{I n^{3+}}$ versus $T^{-1}\left(\mathrm{R}^{2}=0.97\right)$. 

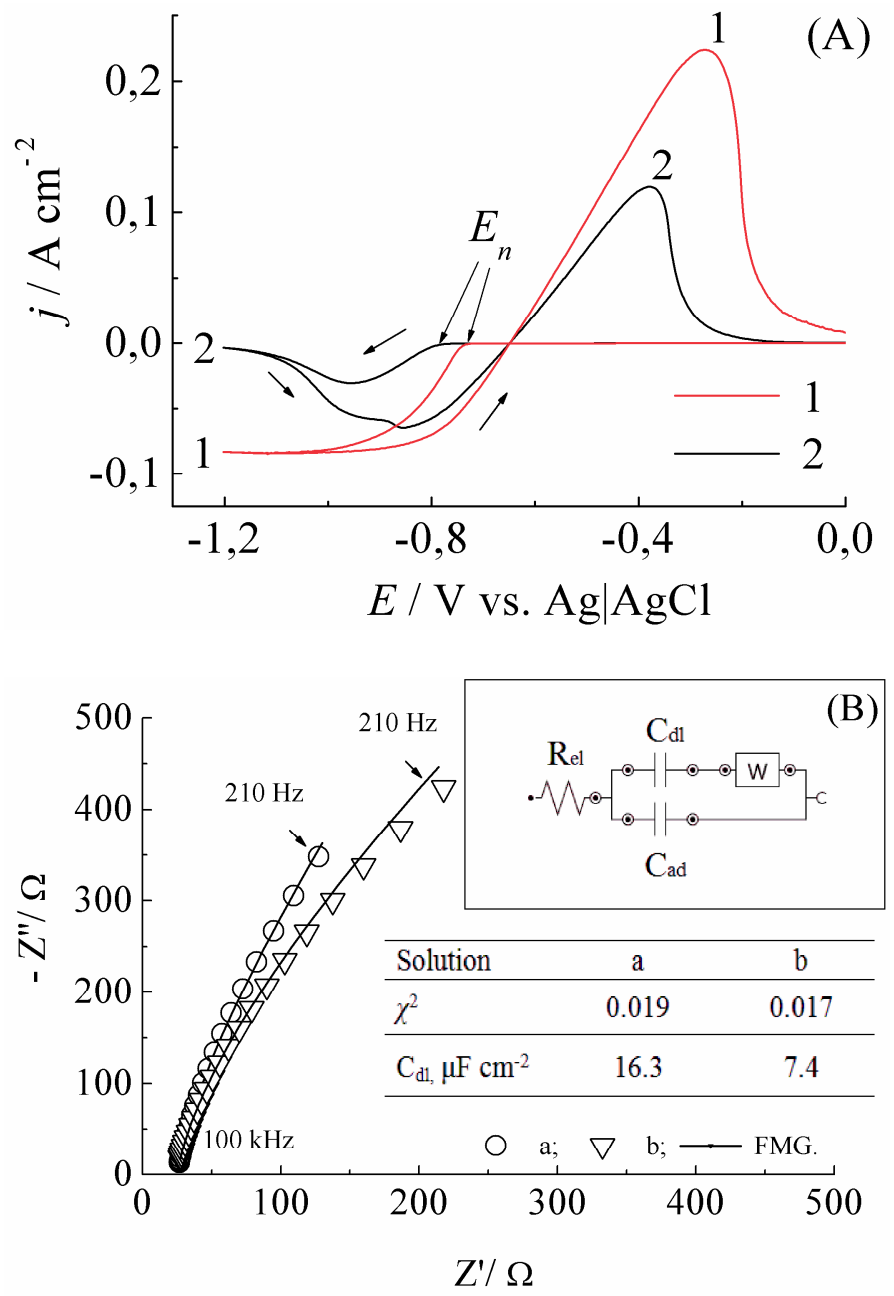

Fig. 4 (A) Cyclic voltammograms performed at the rotation rate $2000 \mathrm{rpm}$ on GC electrode in a blank electrolyte (1) and in the blank electrolyte containing $10^{-4} \mathrm{M}$ TBACh (2). Scan rate of 10 $\mathrm{mV} \mathrm{s}^{-1}$, at $25^{\circ} \mathrm{C}$; (B) Nyquist plots for the glassy carbon electrode in $2 \mathrm{M} \mathrm{NaCl}$ aqueous solutions (a) and with additions of $1 \times 10^{-4} \mathrm{M} \mathrm{TBACh}$ (b) at $E=1.0 \mathrm{~V}$ (vs. $\mathrm{Ag} \mid \mathrm{AgCl}$ ), points experimental data; solid lines - fitting according to the Frumkin - Melik-Gaikazyan model (FMG), at $25^{\circ} \mathrm{C}$. Inset: FMG circuit and the data of the fitting. 

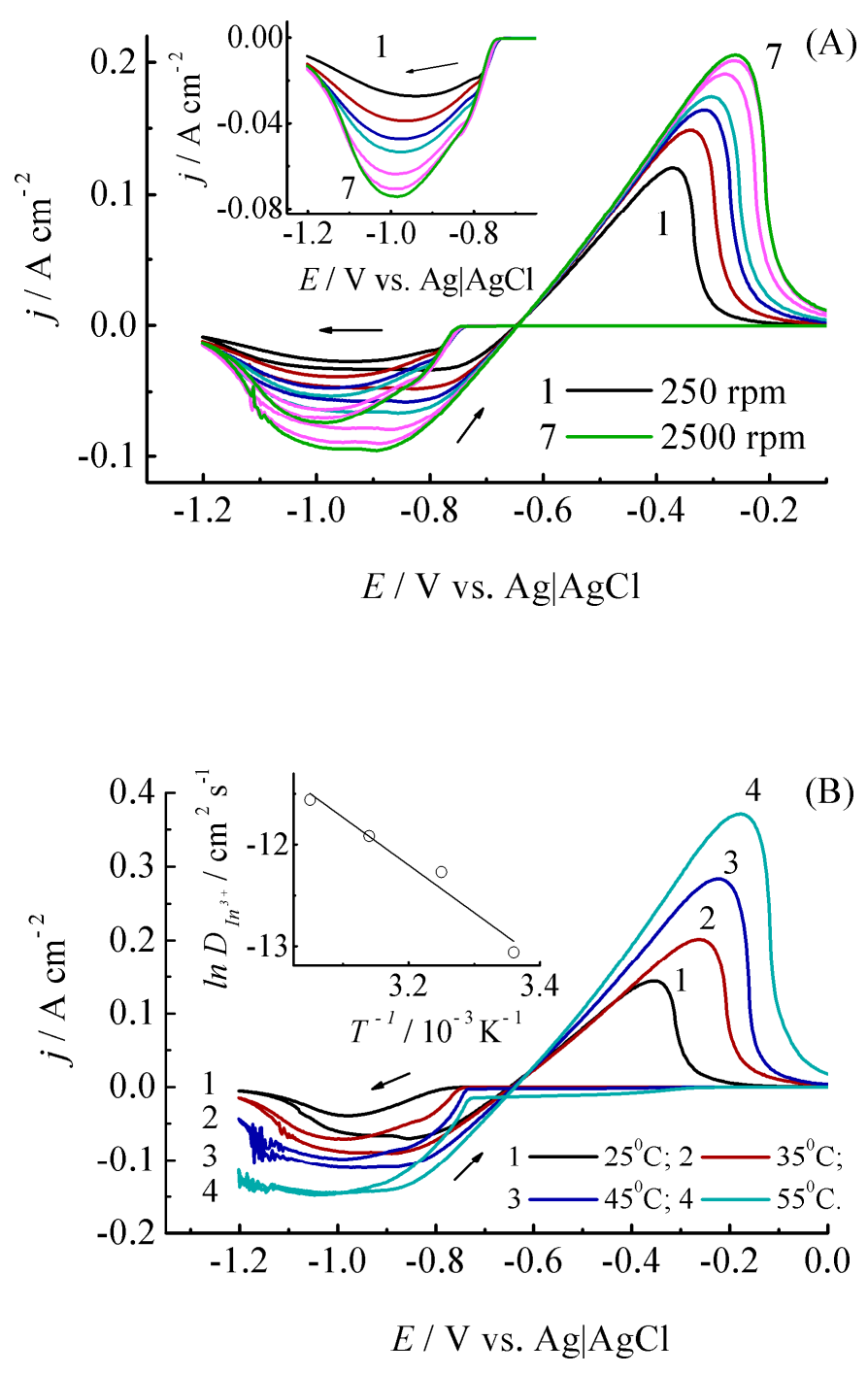

Fig. 5 (A) Cyclic voltammograms obtained at $25^{\circ} \mathrm{C}$ on $\mathrm{GC}$ electrode in a blank electrolyte containing $10^{-4} \mathrm{M}$ TBACh for various rotating rates (250, 500, 750, 1000, 1500, 2000 and 2500 rpm). Inset: forward course of a cyclic voltammograms; (B) Cyclic voltammograms performed at $2000 \mathrm{rpm}$ on GC electrode in the same solution at various temperatures. Inset: evolution of $D_{I n^{3+}}$ vs. $T^{-1}$. 

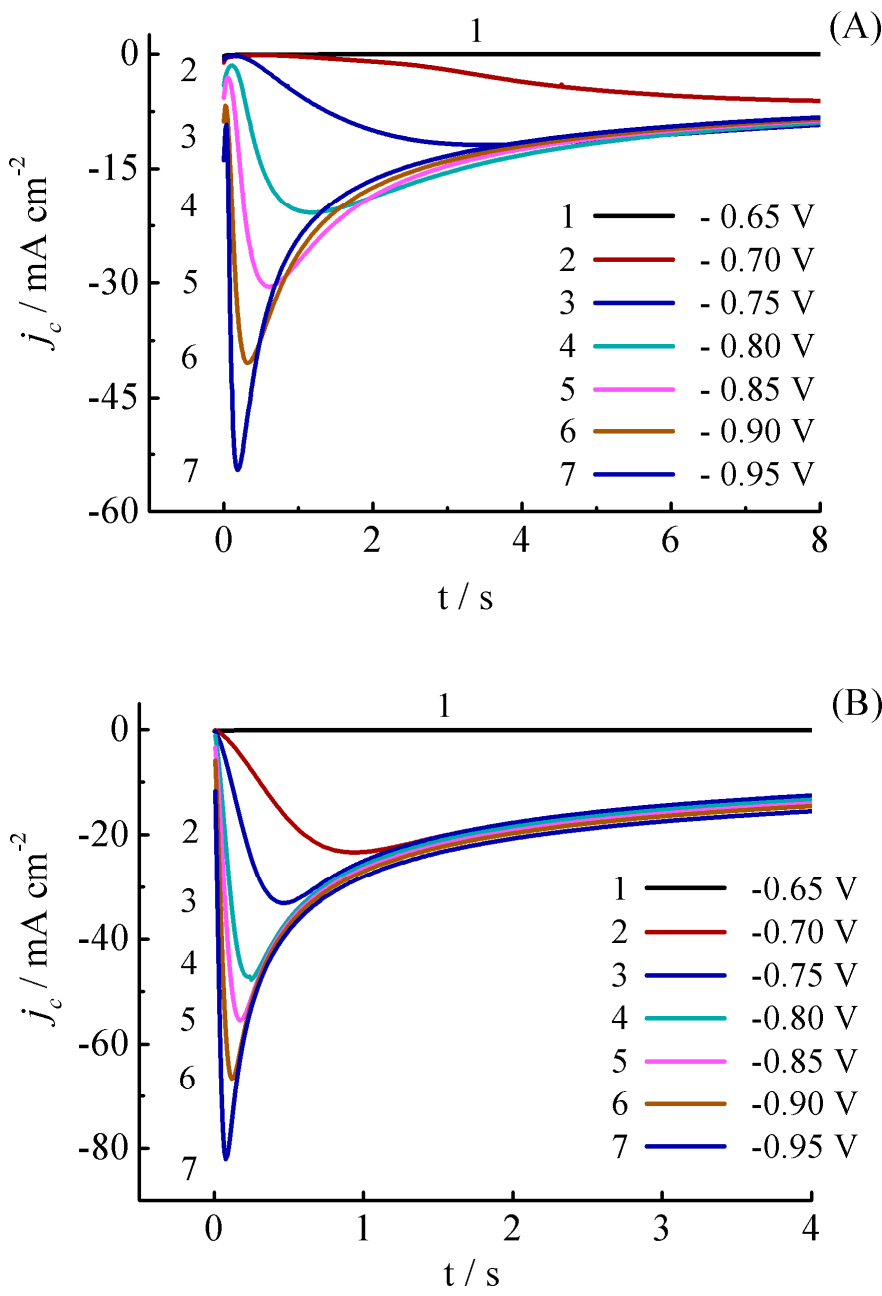

Fig. 6 Potentiostatic transients for the deposition of indium on $\mathrm{GC}$ electrode at $35^{\circ} \mathrm{C}$ temperature from a blank electrolyte (A); from a blank electrolyte $+10^{-4} \mathrm{M}$ TBACh solution (B) for different applied potentials. 

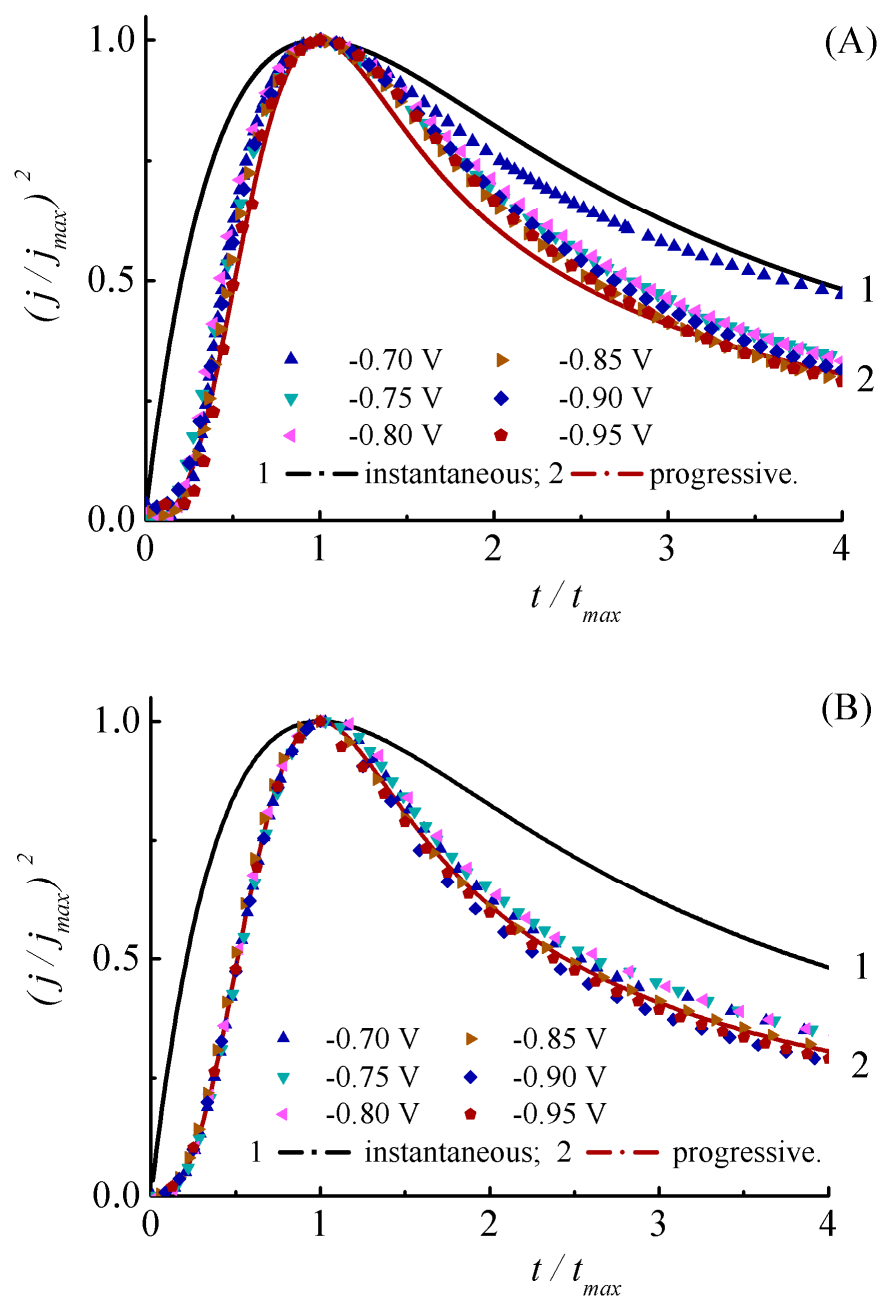

Fig. 7 Dimensionless curves, $\left(j / j_{\max }\right)^{2}$ vs $t / t_{\max }$ experimental (the symbols) and theoretical (the solid lines) for instantaneous and progressive for the indium nucleation at $35^{\circ} \mathrm{C}$ on $\mathrm{GC}$ electrode in a blank electrolyte (A) and a blank electrolyte $+10^{-4} \mathrm{M}$ TBACh solution (B). 


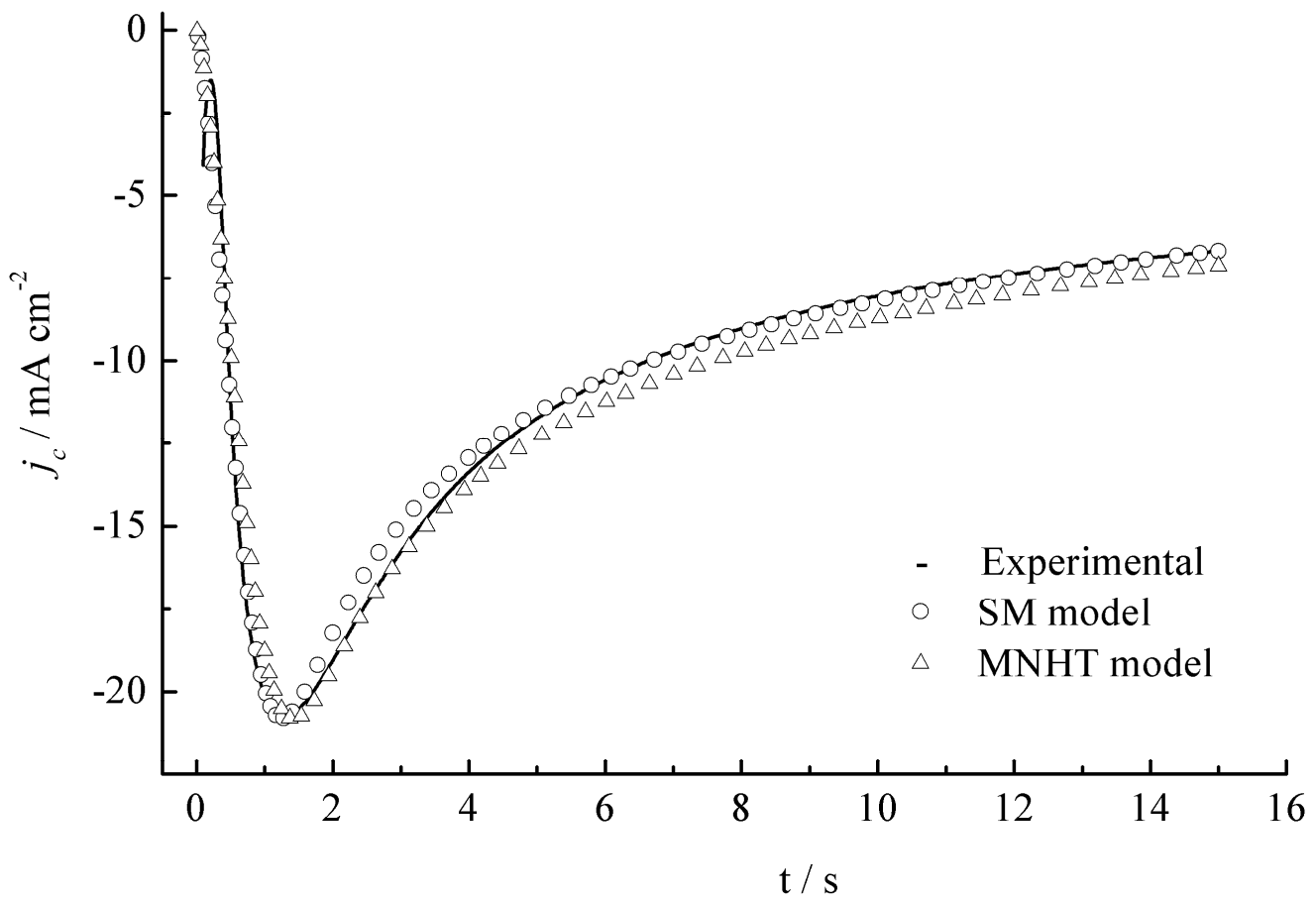

Fig. 8 Experimental (the solid line) and calculated (the symbols) current transients for $\mathrm{D}=$ $6.14 \times 10^{-6} \mathrm{~cm}^{2} \mathrm{~s}^{-1}, \mathrm{c}=5 \times 10^{-5} \mathrm{~mol} \mathrm{~cm} \mathrm{~cm}^{-3}, \rho=7.3 \mathrm{~g} \mathrm{~cm}^{-3}, \mathrm{M}=114.8 \mathrm{~g} \mathrm{~mol}^{-1}, \mathrm{z}=3$ and for SM model $A N_{\infty}=5.78 \times 10^{5} \mathrm{~cm}^{-2} \mathrm{~s}^{-1}$, for MNHT model $A N_{\infty}=4.36 \times 10^{5} \mathrm{~cm}^{-2} \mathrm{~s}^{-1} . E=-0.80 \mathrm{~V}$, at $35^{\circ} \mathrm{C}$. Solution: $0.05 \mathrm{M} \mathrm{InCl}_{3}+2 \mathrm{M} \mathrm{NaCl}$. 


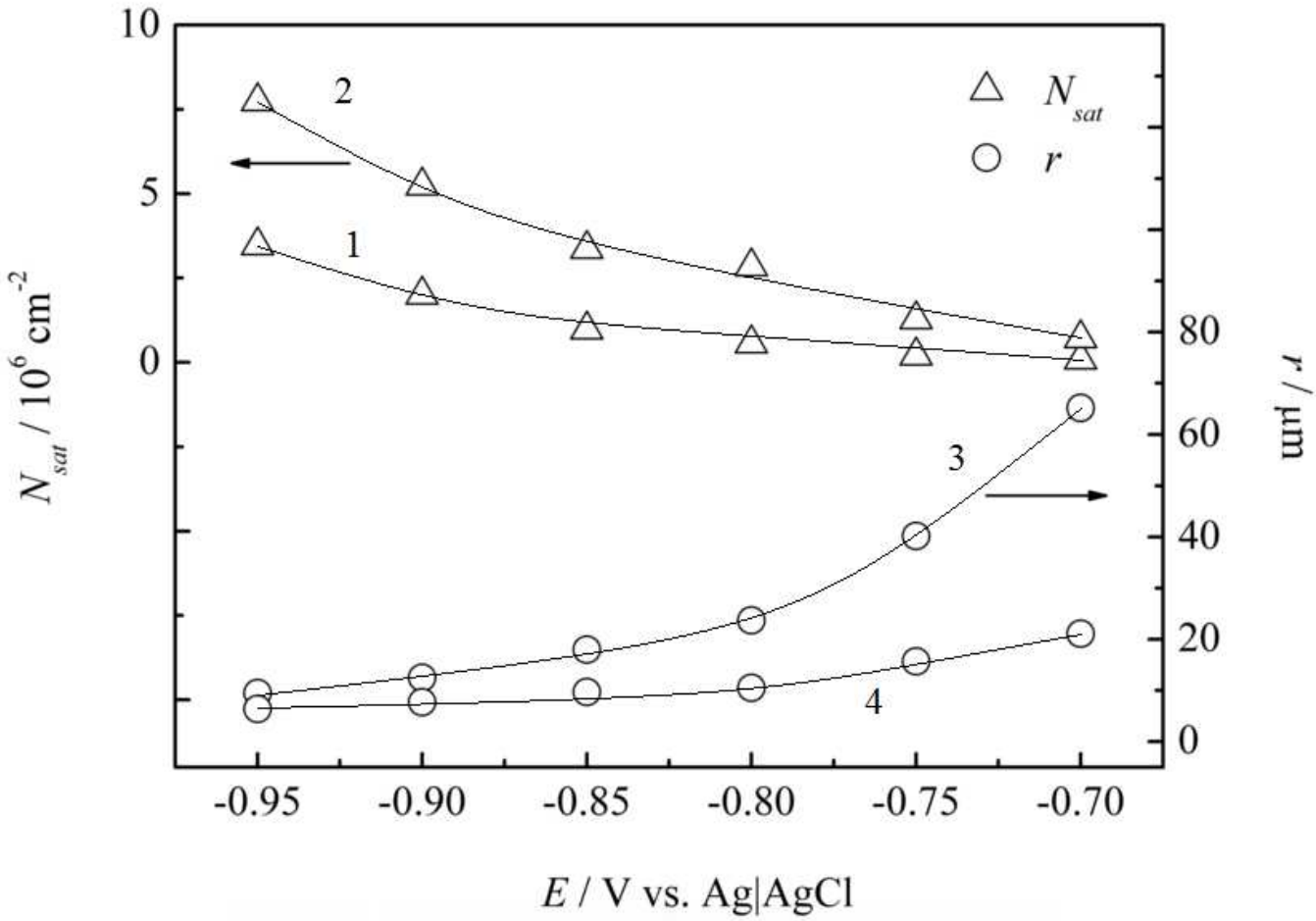

Fig. 9 Dependence of the saturation number density of nucleation active sites, $N_{\text {sat }}$, and the average nucleus radius, $r$, on the applied potential, $E$, obtained by analysis (SH) of the potentiostatic transients presented in Fig. 6 , at $35^{\circ} \mathrm{C}$ in a blank electrolyte $(1,3)$; a blank electrolyte $+10^{-4} \mathrm{M}$ TBACh solution $(2,4)$. 

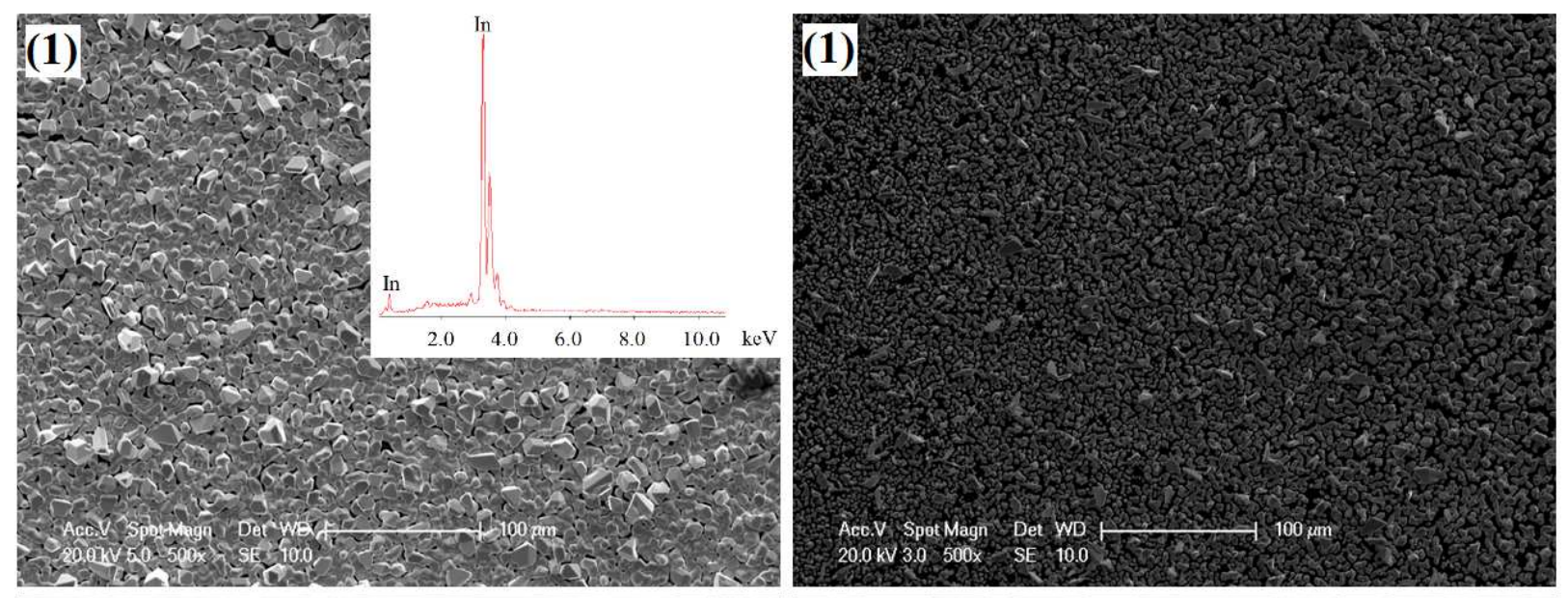

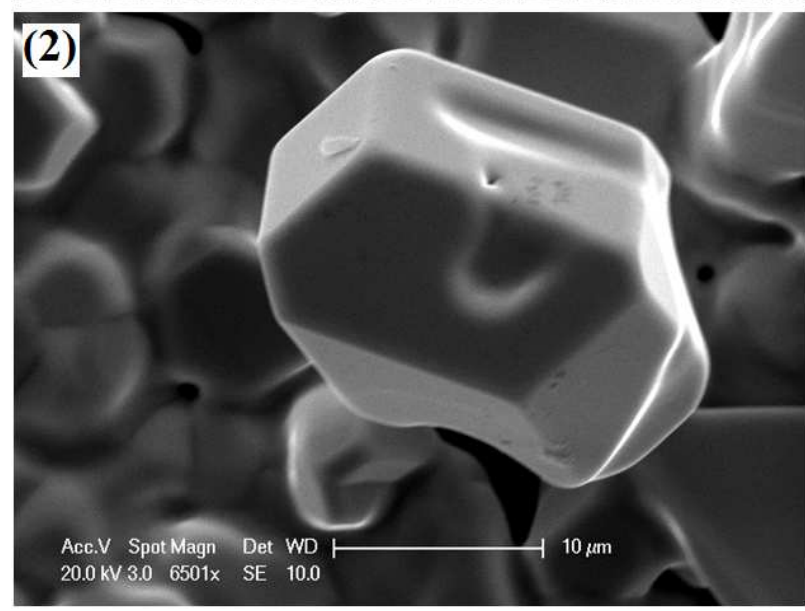

(A)

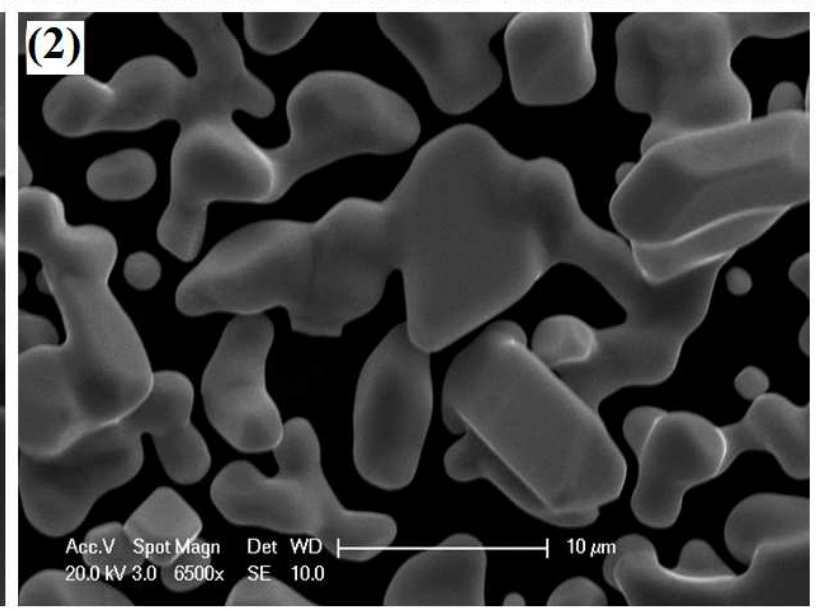

(B)

Fig. 10 SEM images of indium films deposited at $E=-0.90 \mathrm{~V}$ vs. $\mathrm{Ag} \mid \mathrm{AgCl}$, the deposition time $15 \mathrm{~min}$, at $35^{\circ} \mathrm{C}$ from: (A) a blank electrolyte; (B) a blank electrolyte $+10^{-4} \mathrm{M}$ TBACh solution. The different magnification: $(1) \times 500$; (2) $\times 6500$. Inset: EDX analysis of indium coating. 
Table 1 The diffusion coefficients of $\mathrm{In}^{3+}$ ions and the activation energy of diffusion for a blank electrolyte (BE) and blank electrolyte containing $10^{-4} \mathrm{M}$ tetrabutylammonium chloride solution (ME), respectively.

\begin{tabular}{|c|c|c|c|}
\hline \multicolumn{4}{|c|}{$D_{I n^{3+}}\left(10^{-6} \mathrm{~cm}^{2} \mathrm{~s}^{-1}\right)$} \\
\hline \multirow{2}{*}{$T,{ }^{0} \mathrm{C}$} & \multicolumn{2}{|c|}{$\mathrm{BE}$} & \multirow{2}{*}{$\begin{array}{c}\text { ME } \\
\text { RDE method }\end{array}$} \\
\hline & RDE method & Eq. (1) & \\
\hline 25 & 4.93 & 8.99 & 2.13 \\
\hline 35 & 6.14 & 11.39 & 4.69 \\
\hline 45 & 7.67 & 14.07 & 6.68 \\
\hline \multirow[t]{3}{*}{55} & 11.41 & 17.02 & 9.54 \\
\hline & \multicolumn{3}{|c|}{$E_{a}\left(\mathrm{~kJ} \mathrm{~mol}^{-1}\right)$} \\
\hline & & & 39.6 \\
\hline
\end{tabular}


Table 2 Calculated values of the stationary nucleation rate, $A N_{\infty}$ for the $3 \mathrm{D}$ progressive nucleation according to equations 21, 22 [29] for SH model, equations 12 and 13 [27] for SM and MNHT models, respectively.

\begin{tabular}{rrrrr|rrr}
\hline \multirow{2}{*}{$\begin{array}{c}\eta \\
(\mathrm{mV})\end{array}$} & $E(\mathrm{~V})$ & $\begin{array}{c}\mathrm{SH} \\
\text { model }\end{array}$ & $\begin{array}{c}\text { SM } \\
\text { model }\end{array}$ & $\begin{array}{c}\text { MNHT } \\
\text { model }\end{array}$ & SH model & $\begin{array}{c}\text { SM } \\
\text { model }\end{array}$ & $\begin{array}{c}\text { MNHT } \\
\text { model }\end{array}$ \\
\hline 60 & -0.70 & 0.013 & 0.009 & 0.007 & 0.881 & 0.653 & 0.490 \\
110 & -0.75 & 0.087 & 0.064 & 0.049 & 2.834 & 2.068 & 1.550 \\
160 & -0.80 & 0.713 & 0.578 & 0.436 & 14.139 & 10.112 & 7.580 \\
210 & -0.85 & 2.153 & 2.362 & 1.780 & 19.806 & 21.837 & 16.378 \\
260 & -0.90 & 9.188 & 8.920 & 6.690 & 48.086 & 46.685 & 35.014 \\
310 & -0.95 & 27.618 & 27.248 & 20.436 & 105.149 & 100.142 & 75.107 \\
\hline & Solution: & & $\mathrm{BE}$ & & & $\mathrm{ME}$ &
\end{tabular}

